\title{
A noção de felicidade em Freud e Comte-Sponville: Possíveis aproximações e distanciamentos
}

\author{
The notion of happiness in Freud and Comte-Sponville: Possible similarities and differences
}

Carlos Eduardo Firmino[a], Alexandre Frank Silva Kaite ${ }^{[b]}$

\footnotetext{
${ }^{[a]}$ Psicólogo, graduado pela Pontifícia Universidade Católica de Minas Gerais (PUC Minas), analista de políticas públicas da Prefeitura de Belo Horizonte, MG - Brasil, e-mail: firminosq@gmail.com

${ }^{[b]}$ Psicólogo, mestre em Psicologia pela Universidade Federal de Minas Gerais (UFMG), professor da Pontifícia Universidade Católica de Minas Gerais (PUC Minas), coordenador da área clínica de Psicologia do câmpus São Gabriel da mesma instituição, Belo Horizonte, MG - Brasil, e-mail:

akaitel@bol.com.br
}

Recebido: 12/09/2011 Received: 09/12/2011

Aprovado: 03/04/2012 Approved: 04/03/2012

\begin{abstract}
Resumo
Valendo-se de pesquisa bibliográfica, buscou-se no presente trabalho compreender a noção de felicidade discutida por Sigmund Freud e pelo filósofo André Comte-Sponville. Para atingir tal objetivo, as obras $O$ mal-estar na civilização (Freud) e $A$ felicidade, desesperadamente (ComteSponville) foram escolhidas como referências principais. No que diz respeito à concepção freudiana, pode-se afirmar que a felicidade é entendida como um ideal inatingível. Temos acesso a uma falsa felicidade. Na leitura de Comte-Sponville, por outro lado, a felicidade se manifesta em ato, quando não estamos dependentes da esperança. A felicidade é verdadeira e possível. Ambos os autores entendem que a felicidade não é um estado definitivo. Ao final, conclui-se que o ponto principal que diferencia o entendimento de cada autor em relação ao tema é a concepção de desejo que os orienta. Para Comte-Sponville o desejo é visto como potência; para Freud, é visto como falta. Se em Comte-Sponville a felicidade é produção, na concepção freudiana ela é um ideal, já que nosso objeto de desejo está perdido para sempre.
\end{abstract}

Palavras-chave: Felicidade. Desejo. Falta. Potência.

\begin{abstract}
Through literature, we sought in this research to understand the concept of happiness discussed by Sigmund Freud and the philosopher André Comte-Sponville. To achieve this goal, the works The malaise in civilization (Freud) and Happiness, desperately (Comte-Sponville) were chosen as primary references. In relation to the Freudian conception, happiness is understood as something unattainable. We have access to a false happiness. In reading Comte-Sponville, happiness is manifested in action, when we are not dependent on hope. Happiness is real and possible. Both authors believe that happiness is not a definitive state. Finally, we conclude: the main point that differentiates the understanding of each author is the conception of desire. According to Comte-Sponville desire is potency. According to Freud desire is lack. In reading Comte-Sponville happiness is production. In Freudian conception it is an ideal. Our object of desire is lost forever.
\end{abstract}

Keywords: Happiness. Desire. Lack. Potency.

Psicol. Argum. 2013 jul./set., 31 (74), 473-481 


\section{Introdução}

Todo ser humano quer ser feliz. Todos buscam a felicidade. Até mesmo quem decide se enforcar busca, em última instância, pelo menos se livrar da infelicidade. (Pascal citado por Comte-Sponville, 2001). A felicidade é, em certo sentido, uma ordem. Mas, afinal, o que vem a ser a felicidade?

Digamos que a felicidade é algo de difícil definição. Em nosso cotidiano, há quem diga que é a realização de todos os nossos desejos. Há quem diga que felicidade "são momentos". Outros dizem que a felicidade advém de uma avaliação global da existência do sujeito. Para outros, felicidade é encontrar sentido na vida; para muitos, ela sequer existe. São diferentes as concepções acerca do tema. Estas variam dadas as experiências singulares, as idiossincrasias, os valores que orientam a vida de cada um de nós.

Tema frequente e norteador na história do pensamento filosófico, a felicidade, segundo a autora Lillian Graziano (2005), ficou relegada ao campo da autoajuda. No entendimento dessa autora - adepta da chamada Psicologia Positiva - , a Psicologia, calcada num modelo médico, focou seus estudos em distúrbios, disfunções e patologias. A partir daí, as potencialidades do ser humano foram deixadas de lado, deixaram de ser nosso objeto (Graziano, 2005).

Podemos até questionar quais são as potencialidades do ser humano e, inclusive, discordar do exposto pela autora. Mas, um apontamento nos parece certo: se nos aventuramos na lida com a alma humana, em um tempo que não produz formas exitosas de lidar com o sofrimento (Lipovetsky, 2007), o questionamento, a investigação, em suma, a produção teórica sobre o que vem a ser a felicidade se faz necessária.

Nessa perspectiva, buscamos no presente trabalho compreender a noção de felicidade presente no pensamento de Sigmund Freud e do filósofo francês André Comte-Sponville. Com base, principalmente, na leitura das obras $O$ mal-estar na civilização (1930), de Sigmund Freud, e A felicidade, desesperadamente (2001), de André Comte-Sponville, buscou-se neste artigo promover uma discussão entre as ideias de ambos os autores.

\section{Freud e a felicidade}

Em O mal-estar na civilização, Freud (1996a) afirma que o propósito, a intenção, aquilo que os homens buscam e pedem da vida é a felicidade. Seus esforços caminham na direção de um viver feliz, objetivando assim permanecerem. Este é, na leitura freudiana, o objetivo de toda atividade humana: a busca pela felicidade.

Freud entende que essa empresa, a busca pela felicidade, apresenta dois aspectos, duas metas ao redor das quais toda a atividade humana girará: uma meta negativa e uma meta positiva. A meta negativa diz respeito à ausência de sofrimento e desprazer. A meta positiva, por sua vez, refere-se "à experiência de intensos sentimentos de prazer" (Freud, 1996a, p. 84). Para Freud, a felicidade propriamente dita só poderia estar ligada à meta positiva, ou seja, à experimentação dos tais intensos sentimentos de prazer. Grosso modo, a felicidade oriunda da meta negativa pode ser entendida como uma felicidade menor, ou, arrisquemos a dizer, como uma falsa felicidade.

É a partir desse raciocínio que Freud propõe que "o que decide o propósito da vida é simplesmente o programa do princípio do prazer" (Freud, 1996a, p. 84). E, já que em seu entendimento tal programa jamais será executado, pois "encontra-se em desacordo com o mundo inteiro" (Freud, 1996a, p. 84), o alcance do propósito da vida e, consequentemente, a felicidade não foram incluídos no plano da "Criação". 0 homem, para Freud, não está destinado a ser feliz:

0 que chamamos de felicidade no sentido mais restrito provém da satisfação (de preferência, repentina) de necessidades represadas em alto grau, sendo, por sua natureza, possível apenas como uma manifestação episódica. Quando qualquer situação desejada pelo princípio do prazer se prolonga, ela produz tão somente um sentimento de contentamento muito tênue. Somos feitos de modo a só podermos derivar prazer intenso de um contraste, e muito pouco de um determinado estado de coisas (Freud, 1996a, p. 84).

É corolário do postulado que, na medida em que nossa própria constituição limita a possibilidade da felicidade, a infelicidade seja algo mais fácil de ser vivido (Freud, 1996a). 0 motivo? A dimensão do sofrimento sob a qual estamos expostos. 0 sofrimento, diz Freud (1996a, p. 85), "nos ameaça a partir de três direções".

De nosso próprio corpo, condenado à decadência e à dissolução, e que nem mesmo pode dispensar o sofrimento e a ansiedade como sinais de advertência; do mundo externo, que pode voltar-se contra nós com forças de destruição esmagadoras e impiedosas; e, fi- 
nalmente, de nossos relacionamentos com os outros homens. 0 sofrimento que nos provém dessa última fonte talvez nos seja mais penoso do que qualquer outro. Tendemos a encará-lo como uma espécie de acréscimo gratuito, embora ele não possa ser menos fatidicamente inevitável do que o sofrimento oriundo de outras fontes (Freud, 1996a, p. 85).

Ao introduzir a questão do sofrimento, parece ficar mais claro o fato de que os homens tendem a obter aquilo a que chamamos, no presente texto, de felicidade menor. Ora, o que Freud propõe é que a obtenção de prazer (ligada à meta positiva da atividade humana) fica em segundo plano, já que a tarefa de evitar o sofrimento torna-se o objetivo principal. Assim, podemos supor que o que existe, na perspectiva freudiana, é uma espécie de pseudofelicidade. Afinal, o homem, como propõe Freud, pensa ser feliz, "simplesmente porque escapou à infelicidade ou ao sofrimento" (Freud, 1996a, p. 85).

Freud vai além nessa observação e postula que, sob a pressão das possibilidades do surgimento do sofrimento, o homem se acostumou a moderar suas reivindicações acerca da felicidade. A consequência disso é o fato de que "o próprio princípio do prazer, sob a influência do mundo externo, se transformou no mais modesto principio da realidade" (Freud, 1996a, p. 85). Ora, se o princípio da realidade instaura, em certo sentido, o imperativo da adaptação, o que Freud (1996a) aponta é que, dada à limitada possibilidade de alcance da felicidade, o princípio de prazer já não visa mais a busca de prazer em seu sentido estrito. Ele foi moldado e adaptado às condições reais que o mundo externo lhe exige. A ameaça do sofrimento, como exposto, restringe sua atividade.

Freud (1996a) afirma que, diante do sofrimento, o homem busca recursos, métodos que têm como objetivo principal a fuga do desprazer. Destaca, por exemplo, a atitude de distanciamento que alguns tomam para se livrar do sofrimento advindo dos relacionamentos humanos (se este é visto como bastante penoso, o isolamento voluntário surge como uma estratégia possível) e o uso de entorpecentes, substâncias que qualifica como "amortecedores de preocupações" (Freud, 1996a). Afinal, se o sofrimento não é nada além de sensação - só existe se o sentimos - e está relacionado ao modo com que nosso organismo se regula, os métodos mais interessantes para evitá-lo são aqueles que conseguem influenciar o próprio organismo. Nesse sentido, Freud entende que o método químico - a intoxicação - é o mais eficaz (Freud, 1996a). Apesar de tal serviço prestado, o autor afirma que tais veículos intoxicantes são grandes responsáveis, em alguns casos "pelo desperdício de uma grande quota de energia que poderia ser empregada para o aperfeiçoamento do destino humano" (Freud, 1996a, p. 86).

A técnica da arte de viver - "modalidade de vida que faz do amor o centro de tudo, que busca toda satisfação em amar e ser amado" (Freud, 1996a, p. 89) - talvez seja a que mais se aproxima de uma possível consecução completa da felicidade. Nessa técnica não se busca uma fuga do desprazer, nem se tenta romper relações com os objetos do mundo externo. Ela, por outro lado, se prende aos objetos externos e encontra a felicidade a partir do relacionamento emocional com eles. Assim comenta Freud (1996a, p. 89):

Uma atitude psíquica desse tipo chega de modo bastante natural a todos nós; uma das formas através da qual o amor se manifesta - o amor sexual - nos proporcionou nossa mais intensa experiência de uma transbordante sensação de prazer, fornecendo-nos assim um modelo para nossa busca da felicidade. Há, porventura, algo mais natural do que persistirmos na busca da felicidade do modo como a encontramos pela primeira vez?

Ainda assim, Freud (1996a) entende que nessa técnica há um grande risco a qual o indivíduo está exposto. Em seu entendimento, nos tornamos bastante indefesos contra o sofrimento quando amamos, pois a perda do objeto amado pode nos deixar desamparadamente infelizes. De qualquer forma, esta ainda é uma técnica importante na tentativa de obter felicidade.

Um ponto importante a ser pensado acerca da relação entre alivio do sofrimento e busca pela felicidade diz respeito ao lugar paradoxal ocupado pela civilização/cultura. No que diz respeito à lida com o sofrimento causado pelas forças do mundo externo, Freud entende como um bom caminho o ato de "tornar-se membro da comunidade humana e, com o auxílio de uma técnica orientada pela ciência, passar para o ataque à natureza e sujeitá-la ao bem de todos" (Freud, 1996a, p. 85). Encontra-se aqui a ideia — moderna de trabalhar em prol do bem comum. Porém, frisemos o quão paradoxal é tal assertiva. Afinal, lutar pelo bem comum diante das forças da natureza é buscar segurança. 0 paradoxo se encontra no fato de que, ao longo do texto de $O$ mal-estar na civilização, Freud propõe que o homem é infeliz justamente pelo fato de ter de abrir mão de seus desejos e interesses tendo em vista o

Psicol. Argum. 2013 jul./set., 31 (74), 473-481 
objetivo de viver em comunidade e de se manter seguro. No entendimento de Freud (1996a), civilização ou cultura - é a soma de nossas realizações e regulamentos que servem a dois intuitos, a saber, a proteção contra a natureza e o ajustamento das relações mútuas entre os homens. $\mathrm{O}$ autor afirma que se acaso não houvesse uma tentativa de regulação dos relacionamentos, o que estaria em vigor, em disputa, seria a arbitrariedade da vontade individual. Ocorreria que o homem fisicamente mais forte decidiria sempre a seu favor, a serviço de seus próprios interesses e impulsos. A criação de normas de conduta e, consequentemente, de um senso de justiça não é algo natural, mas uma convenção necessária. É a substituição do poder do indivíduo pelo poder da comunidade que marca o passo decisivo da civilização.

Esta assertiva freudiana acerca da inexistência de um senso natural de justiça remete às discussões propostas por Thomas Hobbes (2000). Na perspectiva do pensador inglês, o homem não é naturalmente bom, ou altruísta. Em seu estado de natureza, dirá Hobbes, suas ações são orientadas por um senso de utilidade. A ação humana, num primeiro momento, é guiada pelo desejo de autopreservação, essencialmente egoísta. Daí a necessidade do advento da civilização. Afinal, se cada um de nós mantivesse seu direito - em Hobbes, natural - de fazer tudo o que quisesse, nos encontraríamos numa condição de guerra (Hobbes, 2000).

Assim, para o surgimento da civilização, tornou-se necessário que os membros da comunidade tivessem suas possibilidades de satisfação restritas. Freud (1996a) entende que, enquanto indivíduo, o homem desconhece tais restrições. A civilização é construída sobre a renúncia pulsional, exigindo a não satisfação de moções poderosas. Os relacionamentos sociais são, nesse sentido, baseados naquilo que o autor nomeia "frustração cultural". Nesse ponto, o autor afirma que a privação da satisfação pulsional jamais fica impune. Sérios distúrbios podem surgir caso não ocorra uma compensação na economia de libido do sujeito.

Outra questão que surge ao pensar a organização dos relacionamentos na civilização é o reconhecimento da existência da agressividade humana. Se os homens optam pela vida em comunidade, eles têm de se haver com certo controle de seus impulsos agressivos. Caso contrário, teriam de viver sob a égide da lei do mais forte, citada anteriormente.

Freud compreende que os homens civilizados detectam em si mesmos uma inclinação à agressão. Esse fato faz com que eles suponham, com justiça, a presença desta em seus semelhantes, obrigando-lhes a gastar grande quantidade de energia para garantir a manutenção de seus relacionamentos. 0 autor propõe que existe uma ameaça constante de desintegração da civilização, consequência da "hostilidade primária" presente nos indivíduos.

Não é proposta do presente trabalho se aventurar nas minúcias inerentes ao tema da agressividade no pensamento freudiano. 0 que nos interessa aqui é destacar o lugar que a restrição da agressividade ocupa, conforme o autor, como obstáculo à conquista da felicidade. Afinal:

Se a civilização impõe sacrifícios tão grandes, não apenas à sexualidade do homem, mas também à sua agressividade, podemos compreender melhor por que é difícil ser feliz nessa civilização. ... 0 homem civilizado trocou uma parcela de suas possibilidades de felicidade por uma parcela de segurança (Freud, 1996a, p. 119, grifo nosso).

Como citado no início do texto, o programa de tornar-se feliz, imposto pelo princípio do prazer, não pode ser realizado - temos de frear nossos desejos em prol da civilização. No entanto, Freud (1996a) entende que não devemos - e nem sequer podemos - abandonar os esforços na tentativa de sua realização, seja pela via da obtenção do prazer ou da fuga do desprazer. A felicidade é um problema de economia da libido do indivíduo. Daí, o fato de não existir uma receita, ou como o próprio autor comenta, "uma regra de ouro". Mas, arrisquemos a dizer que, para Freud, nossa felicidade é mínima; nossa felicidade é um engodo.

A leitura de $O$ mal-estar na civilização nos dá a impressão de que a felicidade será verdadeira somente quando realizarmos todos os nossos desejos, fato que nos parece inapropriado já que, como o próprio Freud aponta, seria o ato de "colocar o gozo antes da cautela" (Freud, 1996a, p. 95). A hipotética realização de todos os nossos desejos vai de encontro aos ideais da civilização. Nesse sentido, o que promovemos, na qualidade de seres que partilham da cultura/civilização, é a troca de nossa satisfação por um bocado de segurança.

Se a felicidade em Freud (1996a) pode ser vista como algo menor, uma pseudofelicidade, nossos esforços no sentido de encontrá-la serão sempre paliativos. Pode-se ler na obra freudiana, em suma, uma perspectiva de trabalho que tem como objetivo final 
a minimização do sentimento de infelicidade. Em um texto escrito 12 anos antes da publicação de 0 mal-estar na civilização, ele dá pistas de que essa seria a sua orientação. Nos Estudos sobre a histeria (1893-1895), Freud (1996b), ao ser questionado a respeito da forma como poderia ajudar seus pacientes que sofriam de histeria, disse ser possível a seguinte resposta:

Sem dúvida, o destino acharia mais fácil do que eu aliviá-lo de sua doença. Mas, você poderá convencer-se de que haverá muito a ganhar se conseguirmos transformar seu sofrimento histérico numa infelicidade comum. Com uma vida mental restituída à saúde, você estará mais bem armado contra essa infelicidade (Freud, 1996b, p. 316).

Lidar com a infelicidade comum. Esse parece ser, em Freud, o destino de todos nós, quer sejamos ou não histéricos.

Em uma entrevista concedida, em 1926, ao jornalista norte-americano George Sylvester Viereck, Freud, então com 70 anos, encerra a conversa com um pedido bastante coerente com sua perspectiva de felicidade:

Não me faça parecer um pessimista (disse ele após o aperto de mão). Eu não tenho desprezo pelo mundo. Expressar desdém pelo mundo é apenas outra forma de cortejá-lo, de ganhar audiência e aplauso. Não, eu não sou um pessimista, não enquanto tiver meus filhos, minha mulher e minhas flores! Não sou infeliz ao menos não mais infeliz que os outros (Viereck, 1926).

Tendo sido exposta a perspectiva freudiana, façamos uma leitura do pensamento de Comte-Sponville.

\section{Comte-Sponville e a felicidade desesperada}

O filósofo André Comte-Sponville propõe que, em uma discussão acerca do tema da felicidade, um primeiro ponto a se investigar é a questão do desejo, pois, "ser feliz é - pelo menos numa primeira aproximação - ter o que desejamos" (Comte-Sponville, 2001, p. 25). Nesse ponto, o autor critica a noção platônica de desejo - entendido como falta - e afirma que, se levarmos em consideração aquilo que é proposto em Platão - "o que não temos, o que não somos, o que nos falta, eis os objetos do desejo e do amor"
(Comte-Sponville, 2001, p. 26) - a felicidade se torna algo impossível. Por quê? Porque o desejo é falta, e porque a falta é um sofrimento.Como você pode querer ser feliz se lhe falta, preciosamente, aquilo que você deseja? (Comte-Sponville, 2001, p. 26).

Se o desejo é falta, só desejamos o que não temos. Assim, se ser feliz é ter o que se deseja, torna-se fácil a compreensão dos porquês de não sermos felizes: "Ora, se só desejamos o que não temos, nunca temos o que desejamos, logo nunca somos felizes" (ComteSponville, 2001, p. 28). Isso não quer dizer, aponta Comte-Sponville, que o desejo nunca é satisfeito. 0 que acontece é que após a sua satisfação já não há falta, portanto não há desejo. A partir daí temos o que desejávamos, mas não o que desejamos. "Como ser feliz não é ter o que desejávamos, mas ter o que desejamos $_{\mathbf{2}}$ isso nunca pode acontecer (já que mais uma vez, só desejamos o que não temos)" (Comte-Sponville, 2001, p. 28, grifos do autor). 0 resultado da satisfação do desejo "é o que Schopenhauer chama de tédio, que é a ausência da felicidade no lugar mesmo da sua presença esperada" (Comte-Sponville, 2001, p. 35).

Para Schopenhauer, comenta Comte-Sponville, nossa vida circula entre o sofrimento e o tédio. "Sofrimento porque eu desejo o que não tenho e porque sofro com essa falta; tédio porque tenho o que, por conseguinte, já não desejo" (Comte-Sponville, 2001, p. 35). Como já dito, seguindo tal linha de raciocínio, desejo/falta, satisfação/tédio, a felicidade será algo do campo da impossibilidade, ou como o próprio Comte-Sponville afirma, algo necessariamente perdido (Comte-Sponville, 2001). Já que essa não é a visão do autor - a felicidade é algo possível — é preciso que não sejamos platônicos e, ainda, concluir que tanto Schopenhauer quanto Platão confundiram o desejo com a esperança (Comte-Sponville, 2001). Um pensamento calcado na dimensão da falta traz à tona uma noção de felicidade fundamentada na esperança. E essa não é a proposta do autor:

É que entre a felicidade esperada ("Como eu seria feliz se..") e a felicidade, em outras palavras, entre a decepção, entre o sofrimento e o tédio, há uma ou duas pequenas coisas que Platão, Pascal, Schopenhauer ou Sartre esquecem, ou cuja importância eles subestimam gravemente. Essas duas pequenas coisas são o prazer e a alegria (Comte-Sponville, 2001, p. 41).

Na perspectiva de Comte-Sponville há a possibilidade de um desejo não faltoso. Daí, a importância da alegria e do prazer, no que diz respeito à felicidade.

Psicol. Argum. 2013 jul./set., 31 (74), 473-481 
"Há prazer, há alegria, quando desejamos o que temos, o que fazemos, o que é; há prazer, há alegria, quando desejamos o que não falta" (Comte-Sponville, 2001, p. 42). Podemos ser felizes, sair do ciclo repetitivo de Schopenhauer - e isso às vezes acontece - "porque fazemos o que desejamos, porque desejamos o que fazemos" (Comte-Sponville, 2001, p. 48).

É o que chamo de felicidade em ato, que outra coisa não é senão o próprio ato como felicidade: desejar o que temos, o que fazemos, o que é - o que não falta. Em outras palavras, gozar e regozijar-se... Essa é uma "felicidade desesperada, pelo menos em certo sentido: é uma felicidade que não espera nada" (ComteSponville, 2001, p. 49).

O desespero - produtor dessa felicidade que nada espera - ao qual Comte-Sponville se refere "não é o extremo da infelicidade ou o acabrunhamento depressivo do suicida" (Comte-Sponville, 2001, p. 66). 0 autor usa esse termo para designar, num sentido literal, a ausência de esperança. Se para ser feliz é preciso viver sem esperança, devemos compreender, aponta ComteSponville, que este é um caminho duro. Isso porque perder a esperança - e se haver com o desespero - é algo quase sempre doloroso. Ao ouvir a palavra "desespero", diz Comte-Sponville se escuta uma dor, um trabalho, uma dificuldade. Ainda assim, tal desespero "não é a tristeza, menos ainda o niilismo, a renúncia ou a resignação" (Comte-Sponville, 2001, p. 67). É “um esforço, dizia Spinoza, para nos tornar menos dependentes da esperança..." (Comte-Sponville, 2001, p. 67, grifo do autor).

Sendo um caminho doloroso, poderíamos nos questionar se a esperança surgiria como uma espécie de motor, algo que impulsionasse, dand o certo movimento à vida do indivíduo, sendo, portanto, um importante recurso na busca pela felicidade. A questão é que essa não é a visão de Comte-Sponville. Se a felicidade, retomando o que discutimos sobre a falta anteriormente, está perdida, é justamente pelo fato de que há uma queda nas "armadilhas da esperança sendo a esperança a própria falta ... no tempo e na ignorância" (Comte-Sponville, 2001, p. 36).

Nessa proposta discutida por Comte-Sponville, ao contrário do que poderíamos supor, a esperança não é recurso à felicidade, e sim obstáculo. Para Comte-Sponville, a esperança se fundamenta em nosso desconhecimento, em nosso temor pelo futuro e, ainda, em nossa impotência. Afinal, só esperamos aquilo que não depende de nós. Aquilo cuja satisfação não está submetida ao nosso controle. Em resumo, na perspectiva desse autor, quando tomados pela esperança (da felicidade, de um novo emprego, de uma nova vida etc.) vivemos a desejar sem usufruir de nosso próprio desejo.

Esta ideia coincide com as defendidas por Perls (1985), autor afirma que é a vivência do momento presente e o envolvimento total na tarefa desempenhada que permitem uma vivência mais intensa das emoções, incluída aí a vivência da felicidade. Ao fugir para o futuro, ao ter esperança que em outro tempo seremos mais felizes, acabamos ficando ansiosos e, assim, menos felizes.

Nesse sentido, se a questão do desejo é o ponto inicial para discutir a felicidade, Comte-Sponville aposta que este deverá ser entendido como potência. "O desejo de acordo com Spinoza”, diz o autor, "seria antes essa força em nós que nos permite comer com apetite, agir com apetite, amar com apetite" (Comte-Sponville, 2001, p. 77). Sendo o apetite a própria essência do homem e, em suma, o próprio desejo, como propôs Spinoza (2002), na noç de uma felicidade desesperadora o que caberá a cada indivíduo é conhecer, agir e amar. Conhecendo e tendo vontade do que podemos, há a possibilidade de amar o que não nos falta.

Trata-se de operar uma conversão do desejo... trata-se de aprender a desejar o que depende de nós (isto é, aprender a querer e a agir), trata-se de aprender a desejar o que é (isto é, amar), em vez de desejar sempre o que não é (esperar ou lamentar) (ComteSponville, 2001, p. 87).

Aqui nos remetemos a Perls, Hefferline e Goodman (1997), os quais apontam que o apetite é essencial para a incorporação saudável daquilo que o meio oferece. É por meio do apetite que desestruturamos o que recebemos do meio, assimilando o que nos é nutridor e rejeitando o que é tóxico. Essa assimilação do que nos nutre promove sentimentos de alegria, e a rejeição do que nos é tóxico nos afasta da tristeza.

Longe de ser uma relação de passividade, a ideia de se desejar o que depende de nós, diz respeito a uma postura ativa, até mesmo em relação ao futuro. A saída às armadilhas da esperança não é uma ruptura com o futuro, com o planejamento. A questão da conversão do desejo implica que nossa relação com o porvir seja de gozo, de saber e de poder (Comte-Sponville, 2001). Afinal, propõe o autor, o futuro não nos é totalmente 
desconhecido como se costuma afirmar. "Toda ação supõe uma potência orientada para o futuro" (ComteSponville, 2001, p. 97), numa perspectiva ativa na qual aquilo que está por vir depende do nosso presente. Ora, tal fato instaura a possibilidade de uma relação de confiança, já que conhecemos, e não de esperança. A proposta de esperar menos não exige que deixemos de imaginar e querer ou, ainda, que renunciemos às lembranças. Tal noção de felicidade desesperadora, no entendimento desse autor, não nos prende a um quimérico "viver no instante". Ela se confunde com a busca da sabedoria que é, em última instância, a aceitação do real (Comte-Sponville, 2005). Ainda assim, cabe aqui uma pergunta: em que medida o desejo (ou o apetite) pode ser tratado?

A esse respeito, no preâmbulo da obra Tratado do Desespero e da Beatitude, Comte-Sponville (2006) parece indicar que o desejo poderá ser tratado na medida em que se trata o pensamento. Na concepção do filósofo francês, nossas angústias e dores são, em sua maior parte, frutos de nossa imaginação, fantasias, em suma, de nosso pensamento. 0 pensamento não altera a atrocidade; mas pode ampliá-la. Isso porque, enquanto seres de linguagem e discurso, a partir do pensamento, da imaginação, fazemos com que a atrocidade permaneça em nós, nos obrigando a com ela conviver. A morte não está presente, mas mesmo assim nos atormenta. 0 futuro está por vir, mas ansiamos por ele. Havendo a ausência de qualquer medo, eis que se manifesta a angústia (Comte-Sponville, 2006). Assim, se não somos deuses que podem criar seres, como aponta o autor, o que nos cabe é tentar deslocar o sentido de nosso discurso e, consequentemente, de nosso pensamento. "A única felicidade é um pensamento feliz" (Comte-Sponville, 2006, p. 9).

Entende-se que a felicidade é, em resumo, uma produção do pensamento. Por isso, Comte-Sponville dirá que a infelicidade é sempre um fato. Mas, a felicidade não. Trata-se o desejo - e o pensamento para que esta possa ser inventada. A felicidade existe em ato, como já dissemos. Ou, como argumenta o autor, "no limite: a felicidade não existe. É necessário, portanto inventá-la" (Comte-Sponville, 2006, p. 10, grifo do autor).

\section{Um diálogo acerca do desejo}

Após apresentarmos as principais ideias de ambos os autores, fica o questionamento a respeito daquilo que pode aproximar ou distar as concepções de cada um acerca do tema da felicidade. Não é objetivo do presente trabalho promover uma comparação minuciosa entre as perspectivas de Freud e de Comte-Sponville, haja vista a produção deste escrito se baseou, principalmente, no estudo de uma obra de cada autor.

A partir do exposto até aqui, apontamos que um dos pontos em que divergem as leituras de cada um dos autores no que diz respeito à felicidade é a concepção de desejo. Se para Freud a satisfação é da ordem da impossibilidade, para Comte-Sponville existe uma noção de desejo visto como potência e afirmação. Um percebe o desejo enquanto presença; o outro, enquanto falta. Assim diz Comte-Sponville:

0 fundo do materialismo é o desejo como força e como afirmação, o desejo como potência, o desejo como presença. Aqui. Agora. 0 amor físico nos ensina esta alegria plena, no instante de dois corpos que se entregam, ou de um só que exulta. Carecer? Amanhã, talvez, ou ontem, ou daqui a pouco... Mas no instante presente há tão- somente esta alegria em mim, esta força tensa e poderosa: meu desejo, a alegria triunfante do meu desejo.... o desejo no máximo de sua potência e que não carece de nada (Comte-Sponville, 2006, pp. 250-251, grifo do autor).

Assim, Garcia-Roza (1997) lê Freud:

Portanto, o que caracteriza o desejo para Freud é esse impulso de reproduzir alucinatoriamente uma satisfação original, isto é, um retorno a algo que já não é mais, a um objeto perdido cuja presença é marcada pela falta. Para usar uma fórmula agostiniana, o que caracteriza o desejo é a presença de uma ausência. 0 desejo é a nostalgia do objeto perdido (Garcia-Roza, 1997, p. 145).

Diferentes concepções de desejos orientarão concepções diferentes de felicidade. Sendo o desejo potência, a felicidade é produção. Sendo o desejo faltoso, de característica restitutiva e nostálgica, a felicidade será da ordem do engodo, como dissemos, pois o objeto está para sempre perdido.

Apesar das divergências quanto ao desejo, há algo que permite uma aproximação entre o pensamento desses autores: a ideia de se pensar a felicidade enquanto processo e, ainda, em termos de contraste. Isso aparece de forma clara em Comte-Sponville quando este afirma que a felicidade "é um processo, um movimento, um equilíbrio, só que instável (somos mais ou menos felizes)" (Comte-Sponville, 2005 , p. 88). Sabemos que estamos felizes porque

Psicol. Argum. 2013 jul./set., 31 (74), 473-481 
já vivenciamos a infelicidade. Tal fato faz com que o individuo, quando atormentado pela atrocidade, "saiba, pelo menos por diferença, que a felicidade também existe" (Comte-Sponville, 2000, p. 83).

No que diz respeito ao pensamento freudiano, ilustremos com a leitura feita por Baremblitt (1990) acerca de uma passagem de 0 mal-estar na civilização:

Freud diz que estamos habituados a procurar a felicidade como um estado. Entretanto, sabemos que a felicidade é um contraste e não um estado ... Procuramos um estado de felicidade, mas ... sabemos que a felicidade são momentos, medindo-se por contrastes. Assim, talvez se compreenda melhor o anseio de gozo e a obtenção de prazer, que é o diferencial que se dá entre o gozo procurado, definitivo, permanente, concludente, e uma certa dose que se obteve e que avaliamos depois de tê-la obtido. É a famosa história do que ocorre após o orgasmo. Humoristicamente, o sujeito "pós-orgástico" perguntaria: "Ah... era isto? Foi bom..." (Baremblitt, 1990, p. 82).

Diante do exposto, podemos depreender o seguinte: para Comte-Sponville, a felicidade é um processo, é desesperada e sempre possível. E verdadeira, porque em ato. Para Freud, a felicidade também é um processo, mas é falsa. É um "resto de gozo", já que nosso objeto está perdido para sempre.

\section{Considerações finais}

0 percurso trilhado até aqui permite que sejam produzidos alguns apontamentos ao término do presente trabalho. No que diz respeito à tentativa de compreender a noção de felicidade nas perspectivas de Freud e de Comte-Sponville, depreende-se, em linhas gerais, o seguinte: se para este a felicidade se realiza em ato e tem algo, digamos, de aceitação e afirmação da vida, para aquele a felicidade é da ordem de um ideal inatingível, já que somos constituídos pela falta eterna do objeto que nos daria a satisfação plena.

A concepção de desejo é o principal ponto que diferencia o entendimento de ambos os autores em relação à felicidade. Em Freud, o desejo tem uma característica restitutiva, nostálgica. É marcado pela falta do objeto perdido citado anteriormente. Para Comte-Sponville, influenciado pelo pensamento de Spinoza, o desejo é visto como potência. É marcado por um esforço, pela produção.
Lidar com o desejo e também com o sofrimento parece ser a grande questão que perpassa as interrogações de ambos os autores; questão para a qual não existe, a nosso ver, uma receita pronta. É uma questão do aprendizado de cada um. Aprender o quanto vale a pena suportar isto ou aquilo. Arrisquemos a dizer que não se trata, ainda, de fazer um tratamento do desejo ao modo como proposto por ComteSponville. Há de se questionar o quanto este pode ser tratado. Afinal, como poderíamos tratar algo do qual nem sempre temos consciência?

Talvez, a felicidade esteja ligada ao quanto estamos satisfeitos perante nossas vidas. É uma questão de contentamento. Não o contentamento tênue, do alívio da tensão represada, como proposto por Freud. 0 contentamento aqui discutido tem a ver com a opinião que construímos em relação à nossa vida. Sendo a felicidade algo que não está preso no instante e, ao mesmo tempo, sequer é um estado absoluto, geralmente, nossas opiniões se modificarão ao longo do tempo. Nesse sentido, podemos ser mais felizes atualmente do que fomos no ano passado, por exemplo. Há na felicidade um quê de perspectivismo. Ou seja, algo só poderá ser valorado diante da perspectiva em que a vida se apresenta. Haverá diferentes leituras em diferentes ocasiões.

A grande questão que pesa aqui é o fato de não haver garantia alguma de que determinado caminho possibilita um maior contentamento. Este é um campo no qual as incertezas reinam. Não se pode afirmar que tudo é falta, nem que tudo é potência; nem plenitude, nem sofrimento. No tocante à felicidade, definições estanques deixam a desejar. Sempre.

O mítico conceito da pulsão de morte e a existência do sentimento de culpa, na perspectiva freudiana, são dois temas que mereceriam um estudo mais aprofundado. Em nosso entendimento, tanto a noção de sentimento de culpa quanto a ideia de um possível retorno ao inorgânico apresentam questões que podem tornar ainda mais complexa a leitura da felicidade em Freud. No entanto, um estudo minucioso acerca de tais temas escapa, no momento, ao escopo de nosso trabalho.

\section{Referências}

Baremblitt, G. (1990). Cinco lições sobre a transferência. São Paulo: Hucitec. 
Comte-Sponville, A. (2006). Tratado do desespero e da beatitude. São Paulo: Martins Fontes.

Comte-Sponville, A. (2005). Bom dia, angústia!. São Paulo: Martins Fontes.

Comte-Sponville, A. (2001). A felicidade, desesperadamente. São Paulo: Martins Fontes.

Comte-Sponville, A. (2000). Viver. São Paulo: Martins Fontes.

Freud, S. (1996a). 0 mal-estar na civilização. In S. Freud. Edição standard brasileira das obras psicológicas completas de Sigmund Freud. (Vol. 21, pp. 65-148). Rio de Janeiro: Imago. (Obra originalmente publicada em 1930).

Freud, S. (1996b). Estudos sobre a histeria. In S. Freud. Edição standard brasileira das obras psicológicas completas de Sigmund Freud. (Vol. 2, pp. 271-316). Rio de Janeiro: Imago. (Obra originalmente publicada em 1918).

Garcia-Roza, L. A. (1997). Freud e o inconsciente. Rio de Janeiro: Jorge Zahar.
Graziano, L. D. (2005). A felicidade revisitada: Um estudo sobre bem-estar-subjetivo na visão da Psicologia Positiva. Tese de Doutorado em Psicologia, Universidade de São Paulo, São Paulo.

Hobbes, T. (2000). Leviatã: Ou matéria, forma e poder de um estado eclesiástico e civil. (Os pensadores). São Paulo: Nova Cultural. (Obra original publicada em 1651).

Lipovetsky, G. (2007). A felicidade paradoxal - Ensaio sobre a sociedade de hiperconsumo. São Paulo: Companhia das Letras.

Perls, F. S. (1985). A abordagem gestáltica e testemunha ocular de terapia. Rio de Janeiro: Jorge Zahar.

Perls, F. S., Hefferline, R., Goodman, P. (1997). Gestaltterapia. São Paulo: Summus.

Spinoza, B. (2002). Ética demonstrada à maneira dos geômetras. São Paulo: Martin Claret.

Viereck, G. S. (1926). O valor da vida - Uma entrevista rara de Freud. (P. C. Souza, Trad.). Recuperado em 8 ago. 2010, de http://www.dubitoergosum.xpg.com.br/ a186.htm 